\title{
厦门大学能源化学专业的创建与实践
}

傅钢, 郑南峰, 任斌, 吕金金, 王野, 田中群, 朱亚先 ${ }^{*}$

厦门大学化学化工学院, 福建 厦门 361005

摘要: 厦门大学于 2015 年创建了第一个能源化学本科专业。本文介绍了厦门大学建设的由 11 门组成的能源化学课 程群以及能源化学本科课程体系与教学安排, 总结了能源化学专业建设经验, 特别是理工融合与协同创新的建设思 路, 为兄弟院校申办能源化学专业和开设相关课程提供借鉴和参考。

关键词：能源化学专业；培养目标；课程体系；协同创新

中图分类号: G64; O6

\section{Construction and Practice for Energy Chemistry Majors in Xiamen University}

Gang Fu, Nanfeng Zheng, Bin Ren, Xin Lü, Ye Wang, Zhongqun Tian, Yaxian Zhu *

College of Chemistry and Chemical Engineering, Xiamen University, Xiamen 361005, Fujian Province, P. R. China.

Abstract: Xiamen University established the world's first undergraduate program for energy chemistry in 2015. Herein, we introduced the energy chemistry course group which includes 11 courses. We also described the curriculum system and the teaching arrangement of the undergraduates, and summarized the experience in the construction of energy chemistry major, especially the ideas of science and technology integration and collaborative innovation. We expected our teaching experience would help the other universities to apply for the energy chemistry major and set up relevant courses.

Key Words: Energy chemistry major; Training objectives; Curriculum system; Collaborative innovation

能源是指能为人类提供某种能量形式(如电、光、热、机械能等)的资源, 它不仅是国民经济的重 要物质基础, 也是人类文明的重要支撑。化学与能源的交叉则更加关注从化学角度深入研究能量相 互转化的过程和规律 ${ }^{11]}$ 。2015 年, 厦门大学在国际上首创了 “能源化学” 理学本科专业, 以该专业 为基础申报的 “能源化学研究型人才协同创新培养模式的创建与实践” 分别于 2017 年、2018 年获 得福建省教学成果特等奖和国家级教学成果二等奖。本文总结了厦门大学能源化学专业建设经验, 为兄弟院校申办能源化学专业和开设相关课程提供借鉴和参考。

\section{1 专业设立的背景与基础}

厦门大学化学化工学院拥有悠久的办学历史、雄厚的科研实力、坚实的教学平台和优秀的教学 传统。早在 20 世纪 70 年代, 化学学科设置了与能源密切相关的电化学、催化等本科专业, 并开设

收稿: 2020-08-24; 录用: 2020-09-04; 网络发表: 2020-09-11

“通讯作者, Email: yaxian@xmu.edu.cn

基金资助：国家基础科学人才培养基金项目(J1310024) 
了 “化学电源” “应用电化学” “工业催化” “材料化学导论” 等与能源材料相关的课程。学院长期以 满足国家重大能源战略需求和在化学基础学科领域冲击世界一流为导向, 拥有能源材料化学协同创 新中心 $(i \mathrm{ChEM}) 、$ 固体表面物理化学国家重点实验室、醇醚酯化工清洁生产国家工程实验室、新能源 汽车动力电源技术国家地方联合工程实验室等 5 个实力雄厚的国家级科研平台, 并作为主体参加“中 国福建能源材料科学与技术创新实验室” 建设。学院办学实力雄厚, 拥有化学一级国家重点学科和 化学工程与技术一级学科, 其中化学学科 2017 年成功入选 “双一流” 建设学科, 是首批 “国家理科 基础科学研究和教学人才培养基地”、首批 “国家级实验教学示范中心”、首批 “国家级教学团队” 和国家 “基础学科拔尖学生培养试验计划”, 首批 “基础学科招生改革试点(强基计划)”, 是教育部

“卓越工程师教育培养计划”实施学校和科技部 “创新人才培养示范基地” [2,3]。

能源化学是新兴的交叉领域, 如能结合新工科的理念与思路建设能源化学专业, 必将在世界范 围内抢占能源领域人才培养、学科建设和科学研究等方面的战略制高点, 推动能源产业结构升级, 为实现新一轮跨越式发展提供坚实的科技支撑和丰富的人才资源 ${ }^{[4]}$ 。但在 2015 年以前, 国际上尚未 有系统的能源化学学科体系, 教育部学科分类目录的自然科学门类中亦未设立能源化学学科。为了 让学生在本科阶段就能系统地学习能源化学知识, 浸润式地感受到以能源为牵引的新兴交叉学科的 迅猛发展, 厦门大学确定了 “整合优势资源、创建交叉学科、培养急需人才” 的整体思路, 开始谋 划能源化学建设。2013 年首先在化学专业中创办了 “能源化学” 本科方向, 2015 年获得教育部批准 为本科专业, 2016 年能源化学专业首次招收本科生, 2020 年增列为学士学位授权专业。该专业的设 立, 开创性地从交叉学科的角度为能源科学的发展提供持久的原动力, 为培养理论基础深厚、实验 技能扎实、创新能力强的能源化学领域创新性人才奠定了基础。

\section{2 能源化学专业人才培养目标}

在建设能源化学方向之初, 厦门大学化学化工学院即成立了 “能源材料化学协同创新中心教学 委员会(厦门大学) ” (以下简称 “能源化学教学委员会” ), 负责调研能源、材料、化学相关学科, 并 邀请国内专家研讨, 在充分考虑服务国家战略、经济社会需求以及未来能源化学的发展, 并结合厦 门大学办学定位的基础上, 制定了能源化学专业人才培养目标: 培养热爱祖国, 具有高度的社会责 任感和良好的科学文化素养, 具备深厚的化学和与能源化学相关的基础知识、基础理论和基本技能, 具有扎实的与能源相关学科以及材料学科的知识背景, 具有较强的实践能力和创新能力, 能够在能 源化学及相关领域从事科学研究、技术开发、工程应用、科技管理和教育教学等方面工作的人才。 “能源化学教学委员会” 根据培养目标, 详细制订了该专业学生应具备的知识、素质和能力要求。

\section{3 课程体系}

\section{1 课程体系设置与教学安排}

能源化学是一门综合性学科, 是由能源、化学这两个主干学科并综合材料学、物理学、经济学、 系统论等多个学科融合形成。由于能源化学专业为国际首创, 没有现成的课程体系和教材可供借鉴。 “能源化学教学委员会” 围绕着能源化学人才培养目标和对学生知识、素质、能力的要求, 以 “强 化基础、注重能力、面向前沿、提高素质” 为教学指导思想, 构建了 “宽口径、厚基础” 的能源化 学课程体系, 在无机化学、分析化学、有机化学、物理化学、结构化学的基础上, 设置了能源化学 课程模块。“能源化学教学委员会” 对能源化学知识点进行了梳理, 并通过多方论证, 根据学科逻辑 顺序和学生知识、能力形成的规律将之组合, 创建了 12 门能源化学课程; 在运行的过程中又根据学 科进展、学生反馈等不断进行内容优化、学分调整等, 目前形成了由 11 门课程组成的能源化学课程 群, 具体课程名称和学分设置见表 1 。 
表 1 能源化学课程群

\begin{tabular}{cccc}
\hline 序号 & 课程名称 & 学分 & 层次 \\
\hline 1 & 能源化学导论 & 1 & 能源化学 \\
2 & 能源化学中的数理方法 & 2 & 基础课程 \\
3 & 能源材料基础 & 2 & \\
\hline 4 & 碳资源化学 & 3 & 能源化学 \\
5 & 电化学能源 & 2 & 专业课程 \\
6 & 太阳能转化 & 2 & \\
\hline 7 & 能源化学综合实验 & 2 & 能源化学 \\
\hline 9 & 高等能源化学 & 3 & 前沿进展 \\
\hline 10 & 能源化学工程基础 & 1 & \\
11 & 能源系统工程 & 1 & 交叉学科知识 \\
\hline
\end{tabular}

能源化学专业理论课程体系按能源化学基础课程、能源化学专业课程、能源化学前沿进展以及 交叉学科知识等四个层次构建, 注重课程的系统性, 将工科课程融入其中, 做到理工融合, 同时引 入经济类课程, 增加交叉学科知识, 全面提高学生的综合素养和解决复杂问题的能力。

能源化学专业的学生在入学后的前一年半按化学大类培养, 主要学习化学基础课程, 从大二开 始化学基础课程与能源专业课程并行, 学生须在能源化学课程群共计 20 学分的课程中选修 16 学分, 其中必须含 “能源材料基础” “碳资源化学” 和 “能源化学综合实验”。此外, 要求学生在学期间须 累计参加学术讲座不少于 30 次。

\section{2 能源理论课程群部分课程介绍}

下面将以 “能源化学导论” “碳资源化学” “能源材料基础” “电化学能源” 和 “高等能源化学” 五门课程为例, 简述能源化学各个课程设置的目的、内容和特色。

“能源化学导论” 是能源化学专业的先导性课程, 该课程 1 学分、16 个学时, 开设时间安排在 二年级第一学期。为了使本科生了解能源化学, 该课程设置在在分专业之前, 面向全年段学生, 并 向全校学生开放选修。该课程简述了国内外能源及能源化学领域的全貌和研究应用前景, 特别突出 能源方面的若干重要研究方向和热点问题。要求学生初步学习能源化学各方向的基础知识, 了解国 际和我国能源现状和需求, 学会运用物理和化学基本概念和原理进行相关计算, 把握能源化学研究 中的科学前沿和发展动态。该课程在 2014 级开始面向化学系本科生讲授, 目前面向全校理科学生开 放选修, 前期由田中群院士亲自主讲, 现以田中群院士和傅钢教授双主讲模式进行授课。

“能源材料基础” 是能源化学方向的必修课程, 该课程共 2 学分、32 个学时, 在二年级第二学 期开设。该课程主要内容包括能源相关材料的晶体结构、相变及相平衡, 固体中的扩散, 电子/离子 输运, 热、磁学性质及其材料表征方法等特点和基本规律。要求学生通过该课程的学习, 掌握能源 材料相关的基础知识、基本原理, 了解新型能源材料的种类、制备方法及决定能源材料性能的若干 因素。该课程由国家杰出青年基金获得者杨勇和郑南峰教授按双主讲模式授课。

“碳资源化学” 是能源化学方向的必修课程, 该课程原设计为 4 学分, 分两学期课开设, 通过 两年运行后调整为目前 3 学分、48 个学时, 在三年级第一学期开设。课程内容主要包括碳资源转化 和利用的基本知识与基本理论, 催化化学、电催化及光催化在内的碳资源转化途径研究方法, 如甲 烷、合成气 $\left(\mathrm{CO}+\mathrm{H}_{2}\right)$ 、二氧化碳、甲醇、生物质、石油、煤炭等碳基资源的结构特点、转化利用方 式以及最新研究进展。学生通过课程学习, 掌握碳资源的种类、现状、重要性, 以及碳资源的转化 
利用原理等。该课程由国家杰出青年基金获得者王野教授主讲。

“电化学能源” 是能源化学专业基础课之一, 该课程 2 学分、32 学时, 是厦门大学特色课程之 一。课程内容主要包括电化学储能的原理和基本概念, 一次电池、二次电池、燃料电池和电容器等 电化学储能器件的构成、基本特性和应用方法, 同时介绍以锂离子电池为代表的化学电源的性能演 变及其调控策略、电化学能源材料的理论设计与合成, 以及电化学能源体系的界面过程。学生通过 该课程的学习, 能够掌握电化学能源的基本原理和基本构成, 了解主要电化学储能装置的工作原理、 构成和关键材料, 初步掌握电池、燃料电池、电化学电容器的简单制造工艺和应用方法。该课程主 讲教师为国家高层次人才赵金保教授。

“高等能源化学” 3 学分、 48 个学时, 是本科生和研究生共享的课程, 该课程汇聚了中国科学 技术大学、复旦大学、中国科学院大连化学物理研究所精选的师资力量, 采取专题讲座式教学。主 要内容包括新型能源材料的制备、高新仪器方法对能源材料的表征、能源材料的理论模拟以及能源 材料在催化和光、电化学等领域的应用等。每个专题安排 2-3 个授课单元, 每个单元 3 学时。授课 教师从本科知识水平讲起, 将知识连贯地介绍到该领域最新科研前沿。迄今已邀请到 1 位诺贝尔奖 得主, 7 位中国科学院院士和 4 位杰青头衔以上的教授到校授课, 为本科学生提供了与国际一流学 者在课堂上面对面交流讨论的机会。为了配合课程教学, 使学生更深刻地理解学术前沿动态, 本课 程特遴选厦门大学化学化工学院的青年骨干教师(国家高层次青年人才或国家优秀青年基金获得者) 担任助教, 课后组织学生围绕课程内容与课后思考题开展进一步的学习和讨论。

\section{3 能源化学的实践教学体系}

实践教学是人才培养中不可或缺的重要环节。能源化学需要密切联系理论与实践, 把学生 “体 验性知识” 的获得作为学习的有机构成。能源化学的学生除了须完成化学大类所要求的无机与分析 化学、有机化学和物理化学等相关基础实验和研究性实验外 ${ }^{[4]}$, 针对能源化学的特点还安排了特色 实践教学。

实践教学过程中, 选取能源化学领域最具代表性的研究手段, 精心设计了“能源化学综合实验”。 该课程是能源化学专业学生必修的专业课程, 包括 4 大类 8 个实验, 2 学分、66 学时, 实验内容包 括电极材料的制备与性能测定、催化剂的制备及性能表征、太阳能电池和锂离子电池的制备及性能 评价、多相催化反应理论模拟等, 具体见表 2 。学生通过该课程的学习, 可以初步掌握材料的合成和 表征方法以及重要能源体系的构建、性质与性能表征等实验方法, 培养思维能力、动手能力、观察 能力和处理实验数据、对实验结果进行分析和归纳的能力, 加深对能源体系的原理、概念的理解。

表 2 能源化学综合实验安排

\begin{tabular}{clcc}
\hline 序号 & \multicolumn{1}{c}{ 实验名称 } & 学时 & 类型 \\
\hline 1 & 循环伏安法研究甲酸电催化氧化 & 6 & \multirow{2}{*}{} \\
2 & 直接甲酸燃料电池 & 6 & 催化 \\
\hline 3 & 贵金属上 CO 催化氧化动力学的测试 & 6 & \\
4 & 甲烷部分氧化制合成气负载型金属催化剂的制备、表征和性能评价 & 18 & 多相催化 \\
5 & 光催化产氢 & 6 & \\
\hline 6 & 锂电池的制作与评价 & 12 & 光电储能 \\
\hline 7 & 染料敏化太阳能电池的制备及光伏性能表征 & 6 & 表面模拟 \\
\hline 8 & CO 在 Pd(111)表面氧化机理的周期性密度泛函研究 & 6 & \\
\hline
\end{tabular}

下面将以 “循环伏安法研究甲酸电催化氧化” 和 “光催化产氢” 两个实验为例, 简述能源化学 综合实验的特色。 
“循环伏安法研究甲酸电催化氧化”: 甲酸分子结构简单, 其电催化氧化反应常作为研究电催化 剂的构-效关系和理解电催化反应机理的重要模型反应。循环伏安法是一种电化学常用的暂态研究方 法。该实验要求学生分别绘制不同电位区间的甲酸电氧化循环伏安曲线, 初步掌握如何通过分析曲 线来判断在不同电势范围内可能发生哪些反应, 并据此推测反应机理。

“光催化产氢”: 氢能作为二次能源, 具有清洁、高效等诸多优点, 而利用太阳能实施光解水制 氢则是氢气来源最环保和最可持续的方法。该实验设计的目的是希望学生涉猎光催化这一前沿热点 研究领域, 了解光催化剂设计的常见策略, 并初步掌握光催化性能评价的基本原理和方法。具体实 验中, 要求学生采用溶剂热法和分步光沉积法, 制备 $\mathrm{MnO}_{x}-\mathrm{Pt} / \mathrm{TiO}_{2}$ 光催化剂。光催化剂性能表征实 验要求学生观测光照强度 $I$ 、光照面积 $S$ 、反应时间等控制条件的变化对氢气生成的影响, 并求算反 应的量子效率。

实习是培养创新型人才的重要环节, 可以让学生切身体会能源化学的发展如何带动相关产业升 级迭代。为此, 厦门大学化学化工学院与全球领先的动力电池系统提供商宁德时代新能源科技股份 有限公司签署了共建实践教育基地的协议, 安排学生在生产第一线接受应用研究、技术开发、科技 管理以及就业求职的初步训练。实践内容包括在电芯实际生产线、电化学实验室、研发电芯实验产 线、电芯测试实验室等部门进行轮训。通过实习, 学生们能够初步掌握电池材料表征、电池制作、 电池检测等研发、生产关键步骤, 体会到能源化学相关理论应用到工业生产中所带来的巨大经济效 益, 增强了学生的专业归属感, 激发了学生的学习兴趣和动力, 坚定了专业信心, 提升了他们的专 业能力、安全意识和敬业精神。一名本科生在实训后感言, “短短的 14 天内, 增长了我们的眼界与 见识，使我们对未来的发展和规划有了更加明确的目标与方向。”

\section{4 专业建设的特色}

\section{1 结构优化的师资团队}

高水平创新性人才培养离不开一流教师队伍。目前能源化学专业负责人为田中群教授(院士)和 郑南峰教授(长江、杰青)。11 门能源化学专业课程教学队伍中, 有院士 2 人、长江特聘教授 3 人、 国家高层次人才 1 人、国家杰出青年基金获得者 7 人、国家高层次青年人才 4 人。高水平教师在授 课中将基础专业知识与前沿研究内容结合, 不仅有效地启发了学生的创新思维, 还可充分发挥科研 与教学中的 “传、帮、带” 作用, 形成了一支思想政治素质过硬, 知识结构、年龄结构、学缘结构 合理, 能适应本科教学、论文指导、科学研究的全能型优秀师资团队。同时, 能源化学专业还长期 坚持引进与培养相结合, 一方面吸引国际一流的创新人才(例如诺奖得主), 聘请企业和科研院所中 具有丰富实践经验和教学技能的专家学者来校兼职授课, 另一方面加强本专业青年教师的培养工作, 鼓励青年教师赴国外访学, 学习和借鉴世界先进教育教学经验。

\section{2 理工融合的培养方案}

能源化学培养方案与新工科培养理念高度契合。厦门大学的能源化学专业建设是以引领新能源 技术发展为目标, 以四大基础化学为主干, 以能源化学课程为拓展, 依托化学化工学院的学科优势、 人才优势和科研优势, 打破原有的学科藩篱, 促进理、工学科之间的交叉与融合, 增强原始创新和 集成创新能力。在能源化学的专业培养方案中, 不仅注重夯实学生的数理基础, 开设了 “能源化学 中的数理方法” 课程; 还注重专业和产业对接, 不断深化化学、化工与能效工程的整合, 开设了 “能 源化学工程基础” 和 “能源系统工程” 两门课程。这种理工高度融合的模式有助于培养科学基础厚、 工程能力强、综合素质高的新型人才。

\section{3 协同创新的培养机制}

近代协同理论的创始人哈肯教授指出, 若系统中各子系统(要素)能很好地配合、协同, 多种力量 就能集聚成一个总力量, 形成大大超越原各自功能总和的新功能, 实现 $1+1>2^{[5]}$ 。因此, 协调不 同资源或者个体形成合力, 可以有效促进专业建设。厦门大学能源化学专业在建设过程中借鉴协同 
理论，特别注重协同性，建设了基于协同的人才培养模式，具体体现在以下几方面:

1) 多学科协同。协同数、理、化、能源、经济等学科, 创建了能源化学本科人才培养方案, 注 重强化理科基础, 同时将工科课程融入其中, 在国内首次建设了由 11 门能源化学课程构成的专业核 心课程群, 开设了 8 个能源化学综合实验, 成功解决了理科能源化学本科教学体系缺失的问题。

2) 本科与研究生协同。构建了本科与研究生课程开放共享机制; 实行优秀博士生作为本科生朋 辈导师制度; 建立了初、中、高级循序渐进的本科生科研训练平台, 营造了本科生与研究生共同进 步的良好氛围。

3) 师生协同。完善了本科生导师制, 优秀本科生在学院指导性意见基础上、在导师的指导下制 定个性化培养方案; 构建了师生集中讨论、跨课题组大组会、多元化讲座、跨校学术报告等组成的 师生交流体系，不断探索师生并重的教学过程，实现了师生的协同发展和教学质量的全面提升。

4) 校内外、国内外协同。形成了跨校、多教师联合授课模式; 建立了海外联合培养、学生参加 国际会议和出国交流机制。专门设置了专项学术活动资助基金, 为本科生参加国内外学术活动、到 境外进行短期访学、科研训练等提供学费、生活费、旅费等, 拓宽了本科生的视野, 使他们在交流 中成长。

5) 人才、学科、科研协同。汇集国内乃至国际的能源化学优势力量, 通过协同, 拓展和凝练创 新方向，以高水平师资和高质量的科研带动高素质人才培养。

\section{5 存在的问题与下一步改进}

能源化学学科和专业的建设是一个长期而艰巨的任务, 机遇与挑战并存。其中一个突出问题是 由于学科和专业建设时间短, 目前已正式出版的教材偏少, 不利于学生的自学, 也不利于兄弟院校 参考借鉴。今后应完善激励机制, 鼓励教师撰写相关教材, 鼓励教师申报相关教学教改项目, 加强 国内外教学交流，为引领国际一流学科、培养一流能源化学专业人才奠定基础。

\section{参 考 文 献}

[1] 刘波, 傅强, 包信和, 田中群. 中国科学: 化学, 2018, $48(1), 1$.

[2] 朱亚先, 洪炜, 夏海平, 郭祥群, 吕金金, 杨朝勇, 谢兆雄, 郑兰䔉. 大学化学, 2019, 34 (10), 62.

[3] 任艳平, 吕银云, 郑啸, 林敏, 夏文生. 大学化学, 2019, 34 (10), 95 .

[4] 张树永, 朱亚先, 霍冀川, 宋丽娟, 徐华龙, 郑兰䔉. 大学化学, 2020,35 (10), 6 .

[5] 赫尔曼·哈肯. 协同学: 大自然构成的奥秘. 凌复华, 译. 上海: 上海译文出版社, 2005: 31 . 